


\section{Symbols and narratives of Europe: Three tropes}

\section{ARTICLE INFO:}

\section{Volume: 06}

Issue: 02:2020

Month: March

ISSN: 2459-2943

DOI: 10.18680/hss.2020.0022

Pages: 85-100

LiC.: CC BY-NC-ND 4.0

KEYWORDS:

\begin{tabular}{l}
\hline Europe \\
\hline culture \\
\hline meaning \\
\hline identity \\
\hline mediation \\
\hline symbol \\
\hline narrative
\end{tabular}

\section{ABSTRACT}

ワ hroughout history, attempts have been made to identify Europe as a geographical, political, social, and cultural entity. Recent efforts to establish key symbols and narratives of Europe have focused on a set of central signifying elements, even if there is a wide and contradictory range of ways to define, structure, and interpret them. An introductory remark on the current debate on the need for renewed European self-reflection paves the way for some conceptual clarifications of my approach to concepts like culture, meaning, identity and mediation. A methodological reflection accompanies this on how to use semiotic tools in cultural studies based on critical hermeneutics. The concept of culture used here is based on the signifying practice of mediating meaning-making, linking imagination to communication in a triangular dynamic between texts, subjects, and contexts. Examples are given from two research projects on a broad and diverse range of European symbols and narratives, illustrating such interpretive research results. European identifications are crystallized and spun around three dominant tropes: supreme universality, resurrection from division, and communicative mobility. Their intricate tensions and interrelations attest to how deeply Europe remains a highly contested and dynamic meaning cluster. 


\section{Introduction}

Throughout history, many attempts have been made to identify Europe as a geographical, political, economic, social, and cultural entity. Institutional co-operation requires cultural legitimation through some shared identification of what Europe and Europeanness means and should mean. Two recent research projects on European symbols (Fornäs 2012) and narratives (Fornäs 2017a) indicate that current efforts to identify Europe have focused on a set of signifying elements, even if there is a broad and contradictory range of ways to define, structure, and interpret them. ${ }^{1}$

I will first discuss concepts like culture, meaning, identity and mediation, and then briefly suggest methodological considerations on integrating semiotic tools into cultural studies based on critical hermeneutics. In the next section, I will present and exemplify my interpretations of a diverse range of European symbols and narratives. This leads to a summary of three dominant tropes for European identity, as constructed and contested through different modes of mediated meaning-making investigated in these two projects. Together, these tropes form the interlaced triple-core around which European identifications are today crystallized and spun. Their intricate tensions and interrelations attest to how deeply Europe remains a contested and hence dynamic meaning cluster.

\section{A cultural perspective}

I approach issues of identity from a combined media and cultural perspective. For me, culture is about meaning-making signifying practice, based on triangular interactions between subjects, texts, and contexts, and involving multiple mediations in two key dimensions: a "vertical" process of imagination (making meaning by associating present material things with absent virtual representations) and a "horizontal" process of communication (sharing meaning across distances in time or space) (Fornäs 1995 and 2017b).

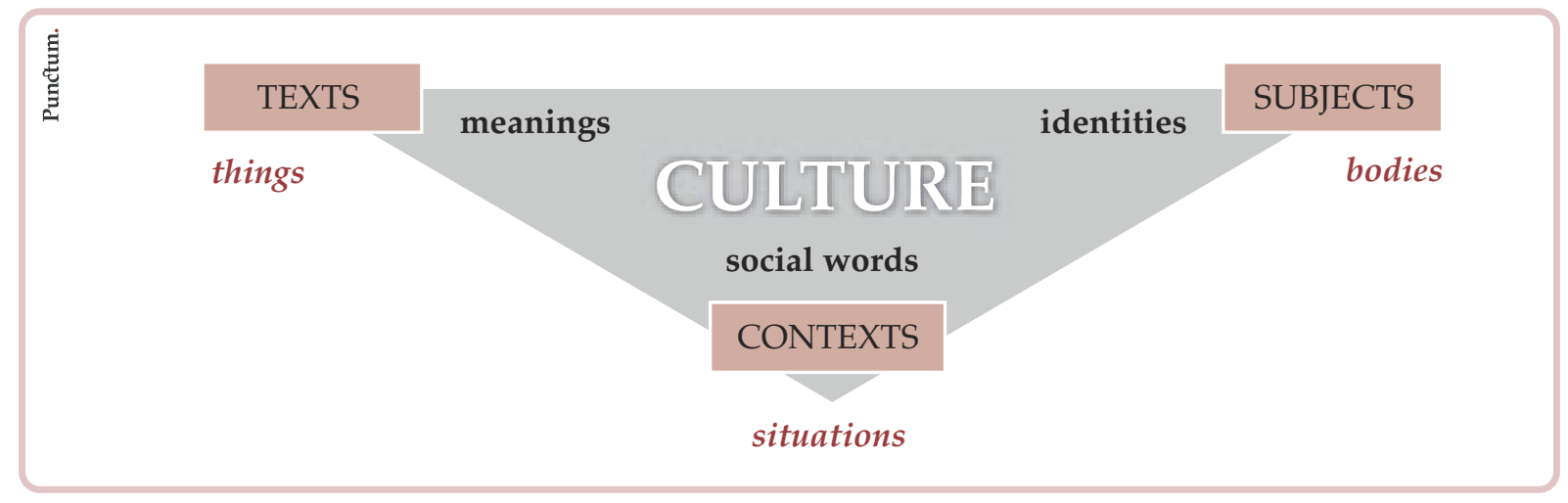

Figure 1. Modelling the translation process through space

1 This text was presented as an invited keynote at the XII International Conference of Semiotics "Signs of Europe" in Thessaloniki, Greece, 2 November 2019. 
In the critical hermeneutic tradition, Paul Ricoeur stressed how culture always implies and requires mediation. Hermeneutics is a theory reflecting upon what people do when they interpret something. I am doing what I see as cultural studies, in the double sense of making interpretations of phenomena perceived as meaningful texts and at the same time studying how people make meanings. As the semiosphere (Lotman 2005, 1990) of communicative processes involving interlinked signs forms culture's defining feature and the inescapable fate of human existence, we cannot escape meaning-making. All human knowledge production makes use of such interpretive practices, which hermeneutics is designed to reflect upon.

From this perspective, meaning-making interpretation does not exclude analytical or structural explanations but integrates them as necessary moments in a dialectical spiral movement between phases of understanding and explanation, synthesis and analysis, guessing and validation, listening and suspicion, proximity and distanciation, reconstruction and disclosure, appropriation and critique. Ricoeur saw structural analysis as providing necessary detours for reaching a more in-depth and better understanding. I similarly see semiotics, discourse analysis, and media archaeology as equally essential tools for that same purpose. Hermeneutics is thus not competing with such other lines of thought, but rather a framework of reflection on meaning-making, allowing for integrating different strategies for qualifying interpretations. Critical hermeneutics does not exclude but, on the contrary, relies on combinations with structural and material approaches and explanations, with the ultimate goal to reach a richer understanding.

Semiotics and other analytical instruments thus do not replace interpretation but are used to understand texts better: "to explain is to bring out the structure, that is, the internal relations of dependence that constitute the statics of the text; to interpret is to follow the path of thought opened up by the text, to place oneself en route toward the orient of the text" (Ricoeur 1971/2008: 117). Interpretation is a processual "dialectic of explanation and understanding" (Ricoeur 1976: 71 and 74), in which explanation through structural analysis serves as necessary "mediation between two stages of understanding" (Ricoeur 1976: 75); "between a naïve interpretation and a critical one, between a surface interpretation and a depth interpretation," so that explanation and understanding are located "at two different stages of a unique hermeneutical arc" (Ricoeur 1976: 87).

Hence, by focusing on mediations and interactional crossroads rather than on closed essences, the critical hermeneutics of culture as signifying practice is a dialectical theory of communicative detours. It may well make use of semiotics to uncover the internal relations of a text, but never forgets to "reconstruct the set of operations through which a work arises from the opaque depths of living, acting, and suffering, to be given by an author to readers who receive it and thereby change their own actions [...] seek- 
ing to reconstruct the whole arc of operations by which practical experience is turned into works, authors, and readers" (Ricoeur 1981: 17 and 18).

\section{Identity, symbols, and narratives}

How to approach the cultural identity of Europe? What can it mean to be European, as expressed in symbols and narratives? There is no one fixed meaning to any identity. Europe has much more than just one single meaning. Stuart Hall emphasized that identities are always multiple, fragmented, dynamic, and contested, acquiring new meanings through the ongoing conflicts of interpretation. In this perspective, Europe is immersed in a dynamic cloud of meanings that evolves through communicative struggles between various European institutions 'from above' and critical movements and citizens 'from below'; between voices understanding themselves as being European 'inside' Europe and those non-European ones, coming from the 'outside' or moving in some peripheral borderland. Interpretations reconstructing layers of meaning in European key symbols and narratives should make it possible to understand how Europe is identified from various directions.

There is now a suspicion that the European political and economic infrastructures lack a sufficiently strong cultural dimension required to make the joint institutions legitimate among citizens. Europe must be made meaningful, to motivate transnational cooperation. For this purpose, several symbols were introduced. Here is a typical formulation of the belief that political symbols can legitimize the European Union and help people identify with it, forming a mutually binding cultural and political community. Political symbols are supposed to help make the European Union more legitimate and construct a political identity that may unite and motivate all Europeans.

Every social group and every organised political society acquires the symbols (or signs) it needs to identify, distinguish and represent itself. [...] A symbol, therefore, acts as a means of identification, as a sign of recognition between people or among the members of a social group. [...] They crystallise national identity by making it tangible [...]. The use of symbols, therefore, has a unifying and federating power. [...] Every political symbol is a tangible sign of identity codifying the shared values that the symbol represents [...]. As in the case of nations, political symbols serve an identifying function for the European Union as well. Political symbols [...] may therefore contribute, by creating emotive images and rites, even subliminally, towards making the European Union more legitimate in the eyes of its citizens and help them to identify with the plan for a common destiny. In other words, they help to construct a political identity, so that a set of values that identify us as belonging to the same community are felt to be binding. (Gialdino 2011 / 2016: 2f) 
Key symbols are generally acknowledged as condensed and essential signifiers of identity for a group, institution, nation, or other social entity. Stuart Hall (1997: 3) placed "the symbolic domain at the very heart of social life." Ricoeur (1994: 130) concurs with structuralism and semiotics in arguing that "symbolism is not an effect of society but society an effect of symbolism." "Social reality is fundamentally symbolic," he argues (Ricoeur 1981: 219), and "there is no self-understanding that is not mediated by signs, symbols, and texts" (Ricoeur 2008: 15).

Reading Europe's meaning(s) requires a mapping of materialities and form-relations and the use(r)s and contexts where these symbols circulate and combine to produce meaning. Historical production and reception contexts also need to be considered since meaning clusters are only provisionally interpreted during their material production and continuously evolve through their reception history (Gadamer's Wirkungsgeschichte). Intertextual comparisons are yet a crucial detour that helps determine what each symbol might mean, and - in this case - what the different symbols of Europe may tell us about how Europe is currently being identified. Combining such aspects and dimensions makes it possible to stepwise reconstruct the meanings of symbols, moving in hermeneutic spiral movements between various techniques of explanation towards an always denser and richer understanding.

While symbols of Europe may just offer a momentary glimpse into what Europeanness may mean, narratives of Europe tell a dynamic story of transformation over time, from past over present to future. Narratives form a genre of symbols with an explicit temporal organization, spun around a series of events with beginning, development, and conclusion. They can be spun around any symbol, but some symbols invite a more obvious temporal interpretation than others, making them narratives. Analyzing and interpreting narratives involves a set of operations. First, defining the set-up: who are the main actors, what is the context of the events that define Europe, and which role does Europe play in this history? Second, mapping the process itself, the sequence of events and actions shaping history as a story. Third, evaluating the narrative mode: its means of construction, its textual genre, and its general attitude towards Europe, in this case. Fourth and final, one may uncover what the narrative signifies: how the story depicts the core meaning (or set of meanings) of Europe.

When narratives trigger collective identification, they may exert considerable influence. But there are many bids on defining or identifying Europe as a collective agency and global actor. Which are its key traits and values? Several different formulations and variants exist, from leading European institutions and various movements, individual thinkers, writers, artists, and media voices. Apparently, they share several elements and aspects while contradicting each other in other respects.

In a European Cultural Foundation seminar report from 2010, Jaap Leerssen formulated a key narrative for Europe in the following terms: "European societies are ne- 
gotiating the catastrophic events of their past on the basis of the notion of reconciliation. And perhaps this is a European master-narrative: the idea that all European nations have a history of bloody, deep fundamental divisions that, at some point, were overcome." At the same time, the European Cultural Foundation (ECF) started looking for "new narratives for Europe," arguing that "Europe has a story to tell": "Many people, especially young people, do not see the need for Europe between the local and the global. Europe as a project for peace and shared welfare, which was the vision after WWII, does not "work" anymore. Even the magic of 1989 is forgotten." A renewal seemed necessary since the old motivations for co-operation, based on the World War traumas, did not suffice anymore. There were two reasons for that, one temporal and one spatial. On the one hand, outside the Balkan area, younger generations of Europeans no longer had personal experience of war. On the other hand, the new member states in ex-communist Eastern Europe must also be fully integrated into the joint project.

In this direction, many efforts tend to focus on high ideals, for example, when Tzvetan Todorov in The New World Disorder: Reflections of a European (2003) listed rationality, justice, democracy, individual freedom, secularism, and tolerance as Europe's leading political values. Ideals indeed contribute to defining identities, but I think it is a dangerous temptation to forget the annoying gap between identity and ideal and imagine that Europe simply equals all its great dreams. It is essential to be equally aware of all the less flattering aspects of what Europe actually is and has been: to acknowledge its defining ambivalences and inner contradictions. A more critical and reflective approach would shed a more nuanced light on the complexities involved in identifying Europe.

Following-up on the ECF initiative, the European Commission in 2013 set up a Cultural Committee, whose distinguished cultural celebrities in 2014 published a report on a "new narrative for Europe." It identified the core values of peace, freedom, democracy, and the rule of law, again in a rather celebratory manner. The committee further suggested that a new narrative for Europe should focus on renaissance and cosmopolitanism as two leading cultural ideals. These imply a narrative that first acknowledges past achievements in need of resurrection and renovation ("a societal paradigm shift"), and second regards the open, communicative urban space as an ideal for the whole of Europe ("Europe as one great mega-city interconnected by means of transportation and communication"). I will return to these ideas later.

European identity has repeatedly been claimed and rejected, cherished and contested - not least, since the formation of European institutions such as the Council of Europe and the geographically more limited but politically more powerful European Union. While some politicians and citizens are skeptical against symbol policies and prefer to concentrate on what they see as more down-to-earth, everyday practices, others find the European project's cultural aspects crucial and underrated. 


\section{Two studies}

I have in two books closely studied first symbols and then narratives of Europe. Intellect Press has made both books available in print as well as by open access. First, in Signifying Europe (2012) and some articles, I investigated a large number of Europe's symbols, starting with those chosen by official European institutions, and then comparing them with alternative versions proposed by other organizations, artists, or individual citizens, as well as with the symbols used by other national or international bodies.

Many different such symbols have turned up over the years, including saints and myths, animals, and plants. The Council of Europe has formally adopted some of them. In the 2004 draft treaty establishing a constitution for Europe, five official symbols were defined. They were then expelled from the final 2007 Treaty of Lisbon, but continue to be used and respected by the EU member states.

1. The European Flag is blue with twelve yellow stars forming a perfect circle. The design with stars on blue has an intricate European history to which I will return later.

2. The European Anthem derives from the final movement of Beethoven's Ninth Symphony. The tune has stylistic and ideological roots in the French revolution, associated with egalitarian enlightenment, determination, and popular togetherness.

3. The Europe Day is 9 May, celebrating the 1950 Schumann Declaration that paved the way for the Coal and Steel Union and then the EU, expressing a determination for peace and welfare after dark times of mutual strife and destruction. The problem is that the Council of Europe instead celebrates its foundation on 5 May.

4. The European Motto wants Europeans to be "united in diversity," not striving to be similar but accepting internal differences and transforming them from obstacles into positive resources.

5. Finally, the Euro Currency is designed to integrate the whole of Europe into a shared space where the banknote windows, doors, and bridges celebrate communication. Simultaneously, the money story from low to high values forms a narrative from Roman antiquity to high modernity. In contrast, the national back sides of the coins again allow for diversity as an asset.

I have analyzed and interpreted all of these in my book, comparing their material and formal elements, users, contexts, and histories of production and reception with similar symbols; for instance, flags for the United States, China, or the African Union, designs proposed by older pan-European organizations, or satirical artworks manipulating the star circle into something else, to highlight hidden deficits in the European project critically.

My interdisciplinary research project "Narratives of Europe" then resulted in a second book, Europe Faces Europe: Narratives from Its Eastern Half (2017), where East European narratives of Europe were mapped and compared, as they circulate in our selected 
discourse fields: phenomenological philosophy (Carl Cederberg), postcolonial geopolitics (Stefan Jonsson), news journalism (Roman Horbyk), Occupy movements (Anne Kaun) and visual art (Katarina MacLeod). My study focused on televised popular music in Eurovision Song Contest (ESC).

\section{Three tropes}

I will try to synthesize these different studies by describing three main tropes found more or less in all of them. There is no single symbol, narrative, or meaning that all agree upon, but one may discern three different tropes that together form a dominant formula for characterizing European identity. All of them are polysemic, open to multiple interpretations. Yet, they together frame a symbolic space that situates discourses of Europe, which is thus, in my opinion, neither a homogenous, fixed, and closed entity, nor a totally elusive, empty sign.

I will present some of the many structural complexities, connections, and contradictions within and between these core tropes while at the same time offering specific and sometimes striking illustrations. The three tropes are centered around Europe's master narrative of resurrection, which I mentioned before. This has three phases: a past golden age, a recent or current experience of internal division and self-inflicted suffering, and a future of reconciliation and renewal through communicative co-operation. These also resonate with three of the general narrative dimensions: set-up, process, and meaning.

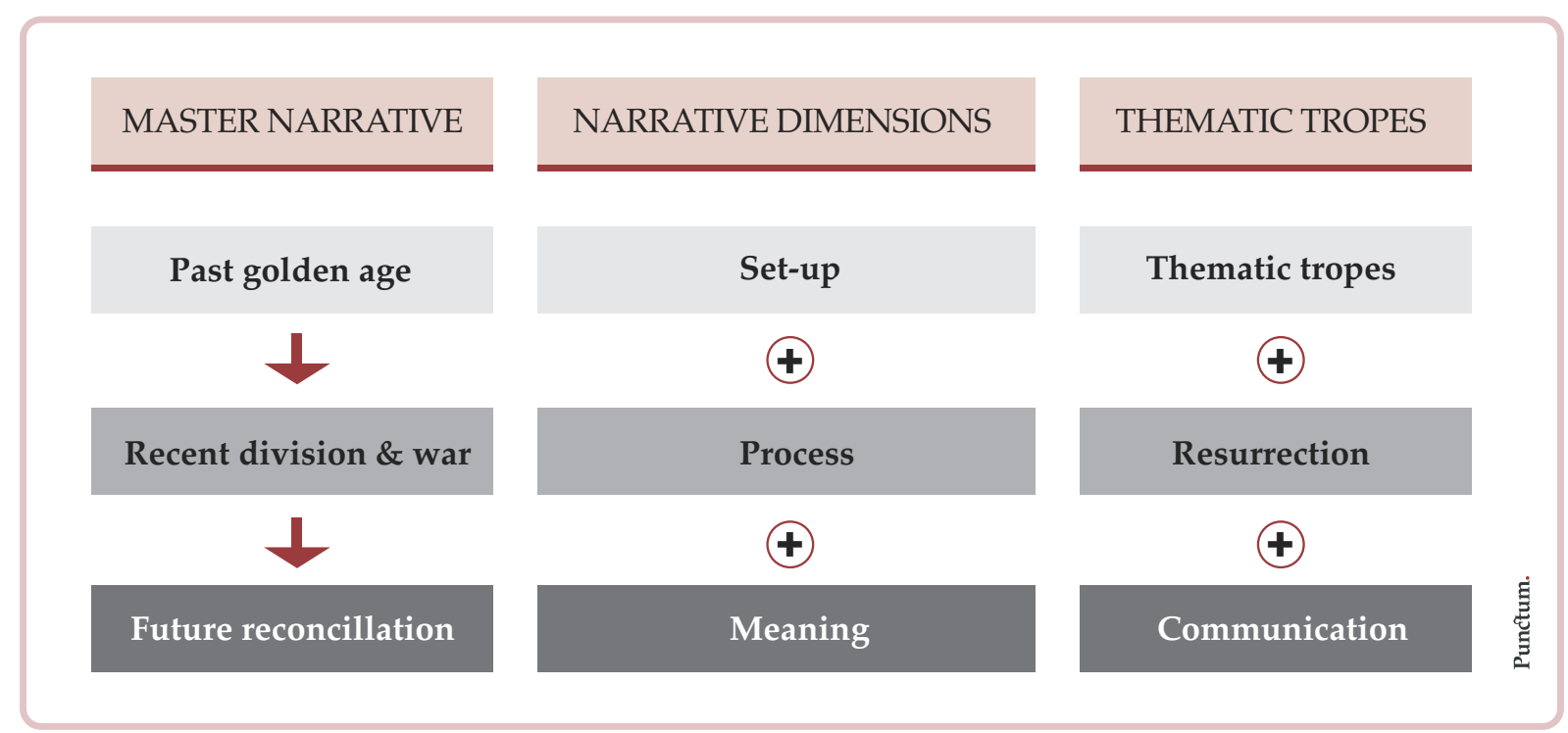

Figure 2. European narratives and thematic tropes 


\subsection{Supreme universality}

The first trope alludes to a supreme universality. Many symbols and narratives share an idea that Europe is somehow chosen for a particularly important mission and challenge, in some way elevated above the other continents. This idea refers to Europe's past achievements in classical Greek and Roman antiquity, Renaissance and Enlightenment modernity, and capitalist industrialization. There is a long heritage of religious, philosophical, and historical thinking of Europe as the cradle of Western civilization, establishing democracy, philosophy, science, and the arts, based on enlightened reason and universal human rights. The theme of nobility or elevation is already found in the myth of Princess Europa, whose abduction by Zeus disguised as a white bull transformed her into a unique founder of a new dynasty of half-divine men. In a similar spirit, Schiller's and Beethoven's anthem describes people intoxicated by Promethean fire, rising to walk in heaven with the gods. An equal pride is found in Eurovision's celebration of Europe's rich cultural heritage.

Paradoxically, Europe's grandeur is founded on a supreme capacity for universality. It appears from its mythical origin to be chosen for the grand mission of global service: elevated to egalitarian universality, which it must share with the rest of the world in a spirit of equality and solidarity. In various disguises, such universalism is inherent in remarkably much of European thinking. From a critical perspective, this serves to underpin a Eurocentric narrative of the West as taking the global lead with its privileged mode of modernity, legitimizing horrible atrocities of crusades and colonialism throughout history. On the other hand, Europe is often associated with human rights discourses, not least in Eurovision. Its anthem, written by DJ Avicii and former ABBA members Benny Andersson and Björn Ulvaeus in 2013, welcomes "a new Enlightenment" with the words: "We are humans born free and equal/ On this one earth lies our future/ Reason, and conscience may they rule the world one day."

By referring back to past achievements, this trope can be said to concern the setup of Europe's narrative, even though the fulfillment of Europe's inherited potentials may still lie in the future. The combination of specificity and universalism is a notoriously tricky one. The ambition to defend universality always risks attracting the accusation of blind imperialist Eurocentrism. An illustration of these tensions was adopting the Ode to Joy theme as the European anthem without Schiller's words. The lack of lyrics mirrors two problematic borderlines for European identification. One argument was that German (or indeed any specific language) was not appropriate since it would not be pan-European but prioritize one nation. If this argument expressed the need to raise the European above the national level, another drew a line between the European and the global, instead. Specifically, the objection was that Schiller's lyrics were too universal, as the phrase "all human beings are becoming brothers" should rather just speak for Europeans. The result was an anthem without words, which is not particu- 
larly well suited for communal singing. The "united in diversity" motto likewise serves to negotiate between the European and the national. There is a risky balance between uniqueness and universality, but their combination seems to be a typical European trait in all my material.

A splendid example of this trope is, of course, the European flag with its perfect star circle, signifying nations that rise together into the sky to guide others. The design may hark back to the saints' halo, the United States' early Betsy Ross flag (1777-1795), or the star flag used by the Central Commission for Navigation on the Rhine, the oldest still working transnational European organization, funded in the early $19^{\text {th }}$ century.

The stars needed to be equal among each other, none bigger or smaller, and all at the same distance from the center. In contrast, the People's Republic of China has one central star signifying the leading role of the Communist Party. But one disadvantage is that the European flag does not indicate any diversity at all. One solution has been the gay movement's insertion of multicolored stars. The EU itself tested another, commissioning the architect and designer Rem Kohlhaas to design the barcode (adopted in 2004), adding all EU's national flag colors beside each other, in a striking image of the motto "united in diversity," but then instead missing the element of elevation. In several cases, there is thus a tension or polarity between stressing equality or elevation, unity or diversity - and an urge to balance them in some way, symbolically as well as in political practice.

Another issue with the flag concerns the circular form. It has been accused of presenting an extreme abstraction that may be universal but empty and sterile. Some have even mocked it for resembling a zero, hence disclosing how empty the European project is and how little Europeans share in common. On the other hand, one may associate it with the circular cosmology and the urban agora of Greek Antiquity. JeanPierre Vernant (Myth and Thought among the Greeks, 1965) has pointed out how classical Greek thinkers like Anaximander adopted a circular model of the world in homology with the main city square where all houses were equidistant from the center. The agora - just like the star circle - might then be understood as an open and shared public space for dynamic dialogues between nations or citizens, which is missing in the Chinese case.

The uses of this symbol confirm this interpretation. For instance, I was once at a conference in Istanbul where they had placed the Turkish crescent inside the European star circle as a temporary actor on the open arena. It may not be officially allowed to do so, but I think that is precisely the kind of symbolic use the star circle allows for one of its main affordances. Is Europe primarily unified or diverse, egalitarian or elitist, empty or open? These are indeed open questions. 


\section{Resurrecting from division}

If the first trope points back towards Europe's birth as an elevation to universality, the second and most important concerns the narrative process itself. It is described in terms of a resurrection from internal and self-inflicted past or present division and perceiving reunification as a new beginning after centuries of destruction. There is now a chance for renewal, rebirth, or a renaissance, based on mutual reconciliation, redemption, and reunification.

I here choose the term 'resurrection' despite its religious subtext. I think that 'renewal,' 'rebirth' and 'renaissance' are in a sense too naïve and smooth terms, as this is not just a refreshing new birth into an innocent childhood. Europe must, on the contrary, remember and answer for its past agonies. Resurrection means to 'rise again' - calling for standing up on one's own feet rather than crawling around and asking to be cared for like a new-born baby.

Even more typical and specific for Europe than the idea of a golden age is this link to radical and self-inflicted war and destruction. This trope is at the core of both the established master narrative of Europe and the European Commission's new narrative. Europe and Europeans have experienced profound misery, which nourished an awareness of precariousness: a vulnerability that motivates a desire for peaceful coexistence and cooperation. This trope appears in the Christian Passion story, Beethoven's Ode to Joy, and the Schuman Declaration.

This experience of loss and pain fuels the dreams of peace so often repeated in Eurovision songs. Singing about suffering is almost only done in songs from East European countries, describing themselves as having grown strong and tough due to such hardships. Without the European downfall into deepest agony, there would not be the profound sense of resurrection that is central to the millenarian narrative. Here are some examples of ESC lyrics of this kind. "We gave tears, and we also gave blood/ May we all have peace in the years to come" (Romania 1996). "We survived the reds and two world wars/ Get up, and dance to our Eastern European kinda funk" (Lithuania 2010). "Differences may not be wrong/ They enrich things that we know / Different faiths, different views / All we can do is to turn them in key" (Hungary 2012). "The ice will melt again, and the leafless tree will blossom/ Every end is just a new beginning/ The curtain opens again" (Estonia 2013)

One single pessimistic exception was Iceland's 2019 song Hate Will Prevail declaring that "Life is meaningless/ Hate will prevail/ Europe will crumble." However, this did not come from eastern Europe, and the European master narrative was ultimately rescued: the performing group, Hatari, insisted that this was just a dystopia in case love and peace would not win the game, which they hoped and worked for. 
The value of resurrection is linked to the previous one of elevated nobility. Wars may destroy the ancient cultural heritage, but they also breed science and technology. Moreover, they indirectly foster culture and reason through the experience of loss that may make Europeans sensitive to others' suffering and one's ethical responsibility. On the other hand, the dialectics of Enlightenment nourish destructive forces but also an intense longing for overcoming them.

The topic of diversity relates to this trope as well. European reunification can never erase its internal differences but only affirm its immanent hybrid diversity. There are slightly different versions of this trope, besides the varying balance between unity and difference. Some symbols and narratives first depict the long-gone golden era, while others take it for granted and start with disastrous misery. Some celebrate resurrection as already achieved when others consider it to remain a key task for the future. There is also a crucial tension between either focusing on the need for peace after self-made internal divisions or freedom from external oppression, which is a pervasive competing theme in Eastern Europe. The latter position may well be reasonable, considering the 20th-century history of these post-communist states. Still, it is in danger of falling back to narratives of revenge, when the "we" tends to regard itself as the innocent victim of external evils, and therefore lacking true responsibility for the necessary reconciliation and renaissance.

\section{Communicative mobility}

A third key value may be derived from looking closer at the third phase of the master narrative: its core meaning. The process of unification is a desire for change, and this temporal change often also entails a spatial shift or reconfiguration: a sense of displacement, dislocation, and mobility. These are ideals, calling for responsible action in the future. Still, they are also deep-seated parts of European experience and identity, as communication has always been a central topic and goal for this continent. This kind of mobility has to do with communication, which is indeed a central value in most European co-operation parts.

In the myth, Europa is abducted from the Middle East to Crete, and her displacement may symbolize how migrations have repeatedly crisscrossed Europe. In Eurovision, artists travel to the host city to meet each other, and their bodies explore new moves on stage, stirring the public's emotions. Broadcasters transmit their tunes to a dispersed European (and tendentially global) audience. Many songs also describe such moves across physical and social space.

Beethoven's Ninth is likewise full of movements, vertically between earth and heaven, horizontally between east and west. Remember that the second ideal for the 'new narrative' suggested by the European Commission was cosmopolitanism, based precisely on communication, mobility, and hybridity. 
There are certainly cases where equality and community develop into homogeneity or even uniformity. One example is the Fortress Europe defended by comic hero Captain Euro fighting against the nomadic D.Vider. However, most voices emphasize that peaceful unification must accommodate difference, making dialogue both necessary and creative, expressed by the motto "united in diversity."

Communication with others is a critical value that is repeatedly signified by lots of these symbols and narratives, striving to transform antagonistic divides into a desire for polyphonic togetherness in diversity. For instance, banknote designs of states and empires mostly feature buildings and rulers of power. This is, for example, true of Chinese or US banknotes. In contrast, the euro banknotes are full of windows, doors, and bridges. They symbolize the stable infrastructures of communication underpinning the soft power of Europe, as a core goal of the EU is, in fact, to secure mobility in several dimensions.

Many of the national coins reverse side also celebrate transnational movements and connections. For instance, this is true of the Greek ships and the national heroes who once sought European support for their independence struggle. Just as the flag recalls the classical Greek agora, the currency name "euro" and its sign based on the epsilon letter honors European civilization's Greek roots. However, in the "moneystory" told by the banknote designs, history instead begins in Rome around the time of the birth of Christ, perhaps because a beginning in Athens four centuries earlier would remind too much of its inherent decentring and pagan hybridity. Greece's euro coin raises the intricate question of whether Greeks or other Europeans identify with Europa as the abduction victim or with Zeus as a virile god and bull. I prefer to acknowledge the sense of migrant displacement lying at the heart of European identity from the very beginning until today.

This last trope is the closest I come to imagine a pivotal meaning to identify what Europe may become. Europe seems filled with a sense of restless and ambivalent dissatisfaction, fueling a constant dynamism of expansion, for good or for worse. No wonder it was the cradle of capitalism, which is now in a prolonged crisis building up to what Rosa Luxemburg saw as an unavoidable choice between barbarism and a postcapitalist social order. The trope of communication interacts with the other two: the unique mobility of capitalism accumulates riches; wealthy empires invest in communications, and Europe's noble universalism is based on trust in dialogical communication. On the other hand, migrations lead to conflict and wars produce refugees, so there is also a negative dialectic of mobility and precariousness.

A series of critical thinkers have formulated values and tasks for Europe in the spirit of the three tropes I discovered. Tzvetan Todorov (1982/1992: 109) argued that "European civilization [...] is 'allocentric' rather than egocentric [...]. The center is elsewhere, which opens up the possibility for the Other to become, someday, central." To 
Rémi Brague (2002), Europe is fundamentally an "eccentric culture" of "secondarity," with a sense of self-defining dislocation, deriving its self-image from the outside. Jacques Derrida (1991) argued for acknowledging difference and alterity for "a Europe still to become." To Zygmunt Bauman (2004: 2 and 7) "Europe is not something you discover; Europe is a mission - something to be made, created, built as an unfinished adventure, defined by its lack of fixed identity and yearning for transgression"; adding that the "European life is conducted in the constant presence and in the company of the others and the different, and the European way of life is a continuous negotiation [...] a transgressive civilization [...] allergic to borders - indeed to all fixity and finitude." Paul Ricoeur (1992 / 1995: 3) proposed a "post-national state combining identity and alterity in a translation ethos of hospitality, mediating between different cultures." Finally, Étienne Balibar (2004: 235) called for Europe as "the interpreter of the world, translating languages and cultures in all directions."

These are all unfulfilled goals, sometimes mistaken for achieved realities, even though they are our particular responsibility because Europe's history has been intimately linked with communication issues. Europe has accumulated significant resources for communicative mobility, but realizing their creative implications remains a task to accomplish rather than a given essence to lean back on. After the euro crisis and Brexit, it became more evident than ever that Europe is "only," first and foremost, a project and a task whose precise character and global role can only fully develop through a series of inevitable political and cultural struggles of interpretation and communication.

The paradigm of communication has shifting implications and applications in different contexts, and an intertextual reading of many different symbols and narratives is needed to do justice to its complexities. I think the master narrative of communicative resurrection remains a relevant one in these fateful times. 


\section{References}

Bauman, Zygmunt 2004. Europe: An Unfinished Adventure. Cambridge: Polity Press. Brague, Rémi 2002 [1992]. Eccentric Culture: A Theory of Western Civilization. South Bend, IN: St. Augustine's Press.

Derrida, Jacques 1991. L'autre cap, suivi de La démocratie ajournée. Paris: Minuit.

European Cultural Foundation 2010. New Narratives for Europe: Seminar 10 May 2010. Amsterdam: ECF.

Fornäs, Johan 1995. Cultural Theory and Late Modernity. London: Sage.

Fornäs, Johan 2012. Signifying Europe. Bristol: Intellect Press (oapen.org/search?identifier $=1000188$ ).

Fornäs, Johan (ed.) 2017a. Europe Faces Europe: Narratives from Its Eastern Half. Bristol: Intellect Press (oapen.org/search?identifier=1000300).

Fornäs, Johan 2017b. Defending Culture: Conceptual Foundations and Contemporary Debate. Basingstoke/New York: Palgrave Macmillan.

Gialdino, Carlo Curti 2011 / 2016. Introduction. In: The Symbols of the European Union. European Navigator (https: / / bit.ly / 3tWx3rX).

Hall, Stuart 1997. Introduction. In: Representation: Cultural Representations and Signifying Practices. London/Milton Keynes: Sage/The Open University, 1-11.

Lotman, 2005 [1984]. On the Semiosphere. Sign Systems Studies 33(1): 205-228.

Lotman, Yuri M. 1990. Universe of the Mind: A Semiotic Theory of Culture. Bloomington: Indiana University Press.

Ricoeur, Paul 1981 [1971]. The Model of the Text: Meaningful Action Considered as a Text. In: Hermeneutics and the Human Sciences: Essays on Language, Action and Interpretation, Cambridge: Cambridge University Press, 197-221.

Ricoeur, Paul 2008 [1971]. What is a Text? Explanation and Understanding. In: From Text to Action: Essays in Hermeneutics II. London/New York: Continuum, 101-120.

Ricoeur, Paul 1976. Interpretation Theory: Discourse and the Surplus of Meaning. Fort Worth: Texas Christian University Press.

Ricoeur, Paul 1994 [1976]. Imagination in Discourse and in Action. In: Gillian Robinson \& John Rundell (eds.). Rethinking Imagination: Culture and Creativity, London: Routledge, 118-135.

Ricoeur, Paul 1981. Mimesis and Representation. Annals of Scholarship II, 15-32.

Ricoeur, Paul 2008 [1983]. On Interpretation. In: From Text to Action: Essays in Hermeneutics II. London/New York: Continuum, 1-20.

Ricoeur, Paul 1995 [1992]. Reflections on a New Ethos for Europe. Philosophy E Social Criticism 21(5/6): 3-13. 
Todorov, Tzvetan 1992 [1982]. The Conquest of America: The Question of the Other. New York: HarperCollins.

Todorov, Tzvetan 2005 [2003]. The New World Disorder: Reflections of a European. Cambridge: Polity.

AUTHOR

Johan Fornäs Professor Emeritus of Media and Communication Studies, Södertörn University, Sweden. 


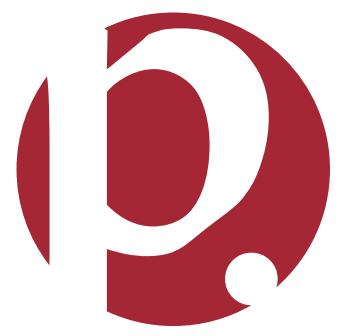

